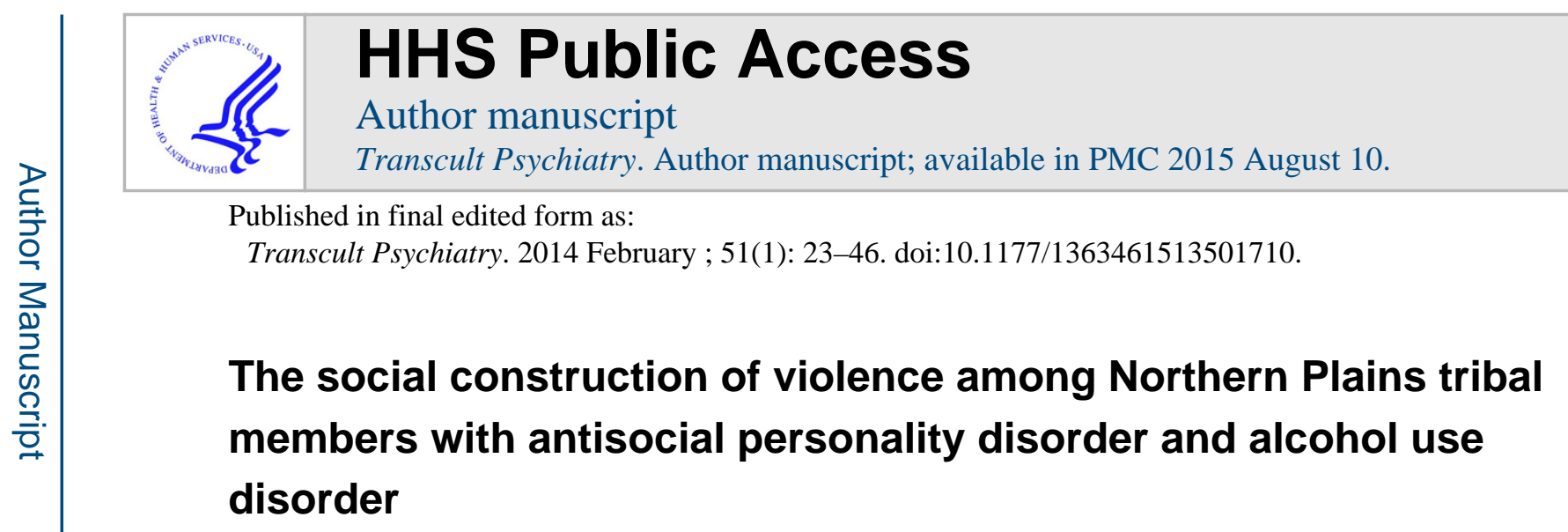

Lori L. Jervis,

University of Oklahoma

Paul Spicer,

University of Oklahoma

Annie Belcourt,

University of Montana

Michelle Sarche,

University of Colorado Denver

Douglas K. Novins,

University of Colorado Denver

Alexandra Fickenscher,

University of Colorado Denver

Janette Beals, and

University of Colorado Denver

\title{
AI-SUPERPFP Team
}

\section{Abstract}

Whereas recent reports from national studies have presented extremely high rates for many personality disorders in American Indian communities, persistent concerns about the meaning of these symptoms have left many troubled by these reports. American Indians as a group are known to suffer disproportionately from a number of violent experiences, but the dynamics of this violence have received little attention. This paper examines perspectives on violence in the lives of 15 northern plains tribal members who met criteria for antisocial personality disorder and comorbid alcohol use disorder. It explores how study participants constructed and understood their own violent encounters, as well as the motivations they described (characterized here as

Reprints and permissions: sagepub.co.uk/journalsPermissions.nav

Corresponding author: Lori L. Jervis, 2 Partners Place, 3100 Monitor Avenue, Room 100 Norman, Oklahoma 73072-7805, USA. lori.jervis@ou.edu.

${ }^{1}$ The AI-SUPERPFP team includes Anna Barón, Amelia Begay, Toni Begay, Cathy Bell, Phyllis Brewer, Nelson Chee, Mary Cook, Helen Curley, Mary Davenport, Rhonda Dick, Marvine Two Eagle, Pearl Dull Knife, Geneva Emhoolah, Roslyn Green, Billie Greene, Jack Herman, Tamara Holmes, Shelly Hubing, Cameron Joe, Louise Joe, Cheryl Martin, Jeff Miller, Robert Moran, Natalie Murphy, Melissa Nixon, Ralph Roanhorse, Margo Schwab, Jennifer Settlemire, Matilda Shorty, Selena Simmons, Wileen Smith, Tina Standing Soldier, Jennifer Truel, Lori Trullinger, Arnold Tsinajinnie, Jennifer Warren, Intriga Wounded Head, Dawn Wright, Jenny Yazzie, and Sheila Young. 
reputation, leveling, retaliation, catharsis, and self-defense). Violence was gendered in this study, with men generally presenting as perpetrators and women as victims. Men often described themselves as ready participants in a violent world, while women were quite clear that aggression for them was often simply required as they tried to defend themselves from male violence. While this analysis does not replace clinical analyses of violence in antisocial personality disorder, it does reveal an underlying cultural logic that may play a role in shaping the recourse to violence for that minority of individuals for whom it appears to be the obvious choice.

\section{Keywords}

alcohol use disorder; American Indians; antisocial personality disorder; gender; violence

\section{Introduction}

This paper explores perspectives on violence in the lives of a group of individuals from a northern plains tribe who met criteria for antisocial personality disorder (ASPD) and comorbid alcohol use disorder. While American Indians are known to suffer disproportionately from a number of violent experiences (Manson, Beals, Klein, Croy, \& the AI-SUPERPFP Team, 2005), the dynamics of this violence and how it is perceived by those who are involved in it—especially by those who have been perpetrators-have received little attention. This paper explores how participants themselves constructed and understood their own violent encounters; these descriptions shared common themes which are summarized in this paper as "typologies" of violent behavior, organized by motive.

As part of a psychiatric epidemiology study, our team carried out ethnographic and clinical research on a northern plains reservation between 1997 and 2000. Throughout the course of this work, the research team was repeatedly struck by descriptions of severe and pervasive trauma. One of the most striking facets of traumatic experience on the reservation was descriptions of violence among fellow community members. As we took a closer look at those individuals who described this violence, we noted that each of them met criteria for ASPD, as well as alcohol use disorder. Although we did not intend to look at people with these diagnoses specifically, our examination of violence required a consideration of these comorbidities. However, we continue to focus primarily on violence because it is not an inevitable consequence of either alcohol disorder or ASPD and, accordingly, it may warrant attention in and of itself (Levy \& Kunitz, 1974; MacAndrew \& Edgerton, 1969; Moeller \& Dougherty, 2001).

It has been suggested that American Indian and Alaska Native individuals may be at higher risk for ASPD (B. F. Grant, Hasin, et al., 2004), but these reports have not considered the contexts in which violent antisocial behavior arises, nor have they considered the DSM-IV guidance that "the clinician ...consider the social and economic context in which the behaviors occur" (American Psychiatric Association, 1994, p. 647) when making a diagnosis of ASPD. The sample described here is in no sense representative of the entire American Indian population, nor even of this specific tribe, but was selected explicitly for accounts of violence in clinical and ethnographic interviews. However, the understandings 
of violence by some of these individuals underscore their perception that violence is a logical, if sometimes unfortunate, choice for them in the context of their life on the reservation. While the data do not permit us to disentangle these self-representations from what some might consider to be justifications for gratuitous or deeply psychologically rooted violent behavior, we argue that the logic revealed here is important to consider in understanding the patterning of violence for that subset of individuals who make these choices, and is an important consideration in any adequate response to the problems we document here.

The defining feature of ASPD, according to the Diagnostic and Statistical Manual of Mental Disorders-IV (American Psychiatric Association, 1994) is "a pervasive pattern of disregard for, and violation of, the rights of others that begins in childhood or early adolescence and continues into adulthood" (p. 645). Symptoms include failure to conform to social norms with respect to lawful behaviors, deceitfulness, impulsivity, irritability and aggressiveness, reckless disregard for one's safety and that of others, consistent irresponsibility, and lack of remorse. In the general U.S. population, ASPD is estimated to affect between $3 \%$ and $5.8 \%$ of males and about $1 \%$ to $1.9 \%$ of females (American Psychiatric Association, 1994; B. Grant, Hasin, et al., 2004; Kessler et al., 1994). A recent study of a national probability sample reported a prevalence of ASPD among Native Americans interviewed using a common diagnostic instrument approaching 10\% (9.7\%) (B. Grant, Hasin, et al., 2004).

The ASPD diagnosis is not without controversy. The whole notion of personality disorders calls into question cultural beliefs and norms about what constitutes an "abnormal personality" or an abnormal pattern of characteristic behaviors and beliefs (Alarcon \& Foulks, 1995). Consequently, there have been concerns about the application of a personality disorder diagnosis such as ASPD to racial and ethnic minority groups with histories of oppression (Lynn, 2002; Skeem, Edens, Sanford, \& Colwell, 2003; Zuckerman, 2003). It has been argued that the diagnosis may be unfairly applied to impoverished groups for whom "antisocial" behaviors can be part of an adaptive survival strategy in often dangerous and threatening environments (American Psychiatric Association, 1994). Finally, some believe ASPD is underestimated among females, with the higher prevalence among males attributed to an overemphasis on aggressive behavior before age 18 (American Psychiatric Association, 1994; Cale \& Lilienfeld, 2002; Nuckolls, 1992; Rutherford, Alterman, Cacciola, \& Snider, 1995). The possibility of these kinds of biases is important to bear in mind given that American Indians as a group have experienced considerable oppression in the postcolonial period (Braveheart-Jordan \& DeBruyn, 1995; Duran, Duran, Yellow Horse Brave Heart, \& Yellow Horse-Davis, 1998; Jervis, Spicer, Manson, \& the AISUPERPFP Team, 2003; Jervis \& the AI-SUPERPFP Team, 2009; Whitbeck, Adams, Hoyt, $\&$ Chen, 2004). Moreover, American Indians are considerably poorer (U.S. Census Bureau, 2007) and experience violent crimes at twice the rate of the U.S. general population (Perry, 2004).

Outside of the ASPD context per se, various aspects of family violence have been explored among American Indians - for instance, child maltreatment (DeBruyn, Chino, Serna, \& Fullerton-Gleason, 2001; Fischler, 1985), intimate partner and family violence (Chester, Robin, Koss, Lopez, \& Goldman, 1994; Evans-Campbell, Lindhorst, Huang, \& Walters, 
2006; Malley-Morrison \& Hines, 2004; Norton \& Manson, 1997; Oetzel \& Duran, 2004; Wahab \& Olson, 2004), and elder mistreatment (Buchwald, Tomita, Ashton, Furman, \& Manson, 2000; Carson \& Hand, 1999; Hudson, Armachain, Beasley, \& Carlson, 1998). American Indian women suffer high rates of sexual assault, often perpetrated by nonNatives (Amnesty International, 2007; Greenfeld \& Smith, 1999). In addition, American Indian gangs and gang violence are increasingly gaining attention in the media, as well as among some academics (Eckholm, 2007; C. M. Grant \& Feimer, 2007; Gray, 2009).

Violence has been consistently linked to alcohol intoxication (Murdoch, Pihl, \& Ross, 1990). For example, assaults, domestic violence, sexual assault, child abuse, and homicide have all shown strong positive correlations with alcohol (Collins \& Schlenger, 1988; Evans, 1980; Moeller \& Dougherty, 2001). Despite the well-established empirical association between alcohol and violence, there are many other important social, cultural, physiological, cognitive, and situational factors that contribute to violence (Collins \& Schlenger, 1988; Evans, 1980; Pernanen, 1991). And while not all individuals with ASPD have alcohol use disorder (Levy \& Kunitz, 1974; MacAndrew \& Edgerton, 1969), these two diagnoses frequently co-occur within the larger U.S. population (Compton, Thomas, Stinson, \& Grant, 2007; B. F. Grant, Stinson, et al., 2004; Moeller \& Dougherty, 2001). Further, people with ASPD are more susceptible to the potential aggression-related effects of alcohol consumption than those who do not suffer from ASPD, possibly due to alcohol expectancies, brain function, and/or brain chemistry (Moeller \& Dougherty, 2001).

Despite the prevalence of violence in Native communities, its relationship to ASPD in this population has seldom been discussed. More often, violence has been examined in relationship to alcohol (Everett, 1980; Jervis et al., 2003; Kunitz \& Levy, 2000; Spicer, 1997). In this article, we take a qualitative look at violence in the lives of individuals with comorbid ASPD and alcohol use disorders, and seek to provide a sense of how it is experienced and represented by the study's participants (Sandelowski, 1986). We begin by characterizing the kinds of violence discussed in the clinical and ethnographic interviews, followed by an examination of the "logic" of violence as constructed and expressed by participants, with an eye toward delineating some of the underlying possible motivations for aggression and the manner in which violence patterns itself within the community.

\section{Method}

This article focuses on 15 American Indian participants (eight female and seven male) who were selected from the larger sample because of their accounts of violence. Participants ranged in age from 18 to 50, with a mean age of 35 (see Table 1). The majority were poor and either married or living as married. Participants had high rates of psychiatric comorbidity. All participants met diagnostic criteria for ASPD and alcohol use disorder based on either the AI-SUPERPFP CIDI (an adapted version of the University of Michigan Composite International Diagnostic Interview [UM-CIDI]; Kessler et al., 1994) and/or an adapted version of the Structured Clinical Interview for DSM (SCID; Spitzer, Williams, \& Gibbon, 1987); the majority also met criteria for major depressive disorder, posttraumatic stress disorder, and drug abuse/dependence. 
The sample described above was a subsample of a larger study, the American Indian Service Utilization, Psychiatric Epidemiology, Risk and Protective Factors Project (AI-SUPERPFP), which was one of the first large-scale population-based studies of psychiatric epidemiology in Native populations (Beals, Manson, Mitchell, Spicer, \& the AI-SUPERPFP Team, 2003). The purpose of the overall project was to comprehensively examine alcohol, drug, and mental health issues, as well as service utilization, in select American Indian reservation communities. AI-SUPERPFP was comprised of several components: (a) structured interviews using the AI-SUPERPFP adapted version of the UM-CIDI (Kessler et al., 1994) were conducted with a random sample of 3,084 tribal members aged 15 to 54 living on or within 20 miles of one of three reservations and examined diagnoses, risk/protective factors, and service utilization; (b) clinical interviews using the SCID (Spitzer et al., 1987) were conducted with a subset of 335 individuals who had participated in the initial structured interview, three quarters of whom met lifetime criteria for one of four DSM-IIIR disorders: major depressive episode, alcohol abuse/dependence, or posttraumatic stress disorder, as determined by the UM-CIDI (Kessler et al., 1994); and (c) ethnographic interviews with 89 participants who had participated in either of the earlier phases of the study.

The data here are derived from one of the northern plains reservations, referred to by the pseudonym Grass River. Figure 1 shows the sampling strategy as it applies specifically to the Grass River reservation. The study received tribal approval and university institutional review board (IRB) approval prior to data collection.

The clinical interviews were conducted by a team of eight psychiatrists and clinical psychologists with experience in Native communities. The goal was to assess concordance between the AI-SUPERPFP CIDI and the SCID (Spitzer et al., 1987). Although clinical interviews were primarily concerned with obtaining diagnoses for the purposes of validating the AI-SUPERPFP CIDI, they yielded much in-depth discussion of participants' lives and concerns. In addition to the semistructured diagnostic interview module, the SCID included questions about participants' background, life circumstances, and the most difficult and best times the participant had experienced. These questions, along with the fact that participants often elaborated a great deal when answering SCID symptom questions, yielded a rich and substantial body of data. The mean length of SCID interviews was 95 minutes, ranging from 25 minutes to 265 minutes. The range in interview duration was mostly accounted for by the degree of verbal elaboration and diagnostic complexity, but is also a testament to the richness of the data.

The primary purpose of the study's ethnographic component, which consisted of unstructured interviews by the first author, an anthropologist, was to elucidate cultural expressions of distress by contextualizing the larger project's diagnostic findings within participants' broader understandings of self and reservation life. Referrals were obtained primarily from clinical interviewers, who considered a broad set of cultural, diagnostic, and clinical criteria, as well as their perception of participants' interest in and ability to reflect upon these issues. These referrals were obtained in a forum that was known as "clinigraphy" (a fusion of the terms "clinical" and "ethnography") and that brought clinicians and ethnographers together to discuss the importance of a particular participant's narrative. 
Ethnographic interviews lasted 82 minutes on average, with a range of 20 to 210 minutes. Participants were informed that the purpose of the study was to learn about mental health issues in their community, and that the goal of the interview was to learn more about their experiences. Participants were told they were free to start where they wished and to discuss what they wished, and if they preferred, they could start by discussing their growing up years. The majority of interviews required very little interviewer prompting after this set-up. No specific questions were systematically asked about violence or specific diagnoses in these interviews.

As with the SCIDs, ethnographic interviews were audiotaped and transcribed verbatim. They were originally analyzed as part of AI-SUPERPFP, and then more recently subjected to a more exhaustive analysis as part of a secondary data analysis project. This process involved team coding (Guest \& MacQueen, 2008) of over 10,000 single-spaced pages of both ethnographic and clinical interview transcripts by the clinigraphy team. Interviews were coded for conceptual themes using NVivo 7 (Qualitative Solutions \& Research, 2006). This process involved jointly developing a codebook of 26 parent codes, each with numerous subcodes. Once coding commenced, the team regularly conducted reliability checks to ensure that codes were applied consistently across transcripts, and developed memos focused on analyzing specific cases (Guest \& MacQueen, 2008; O'Reilly, 2009; Strauss \& Corbin, 1990). The findings presented here draw upon the qualitative analysis of both clinical and ethnographic interview transcripts.

As we take on this work, we are mindful of the potentially stigmatizing nature of the subject matter at hand. Philippe Bourgois (2002), who worked with Puerto Rican crack dealers in East Harlem, wrote about the challenges ethnographers face when researching and writing about ugliness in the lives of people with histories of oppression:

Most ethnographers offer sympathetic readings of the culture or people they study. Indeed, this is enshrined in the fundamental anthropological tenet of cultural relativism. Cultures are never good or bad; they simply have an internal logic. In fact, however, suffering is usually hideous; it is a solvent of human integrity, and ethnographers never want to make the people they study look ugly. (p. 15)

Our struggle here, then, is to present findings about violence among a relatively small group of American Indian people with ASPD and alcohol use disorders- some of which are disturbing - without contributing to stigmatization of Native people as a whole, the vast majority of whom do not engage in this kind of violence or suffer from these disorders. Here it is important to note that the individuals described in this article were part of a select sample and represent only $1.1 \%$ of the overall northern plains sample in AI-SUPERPFP; thus, there is no reason to assume that their violence is typical of the larger group. With respect to their diagnoses, the prevalence of lifetime alcohol use disorder in the overall northern plains sample was 34.7\% (Beals et al., 2005), while ASPD ranged between 6 and 13\% (Fickenscher, Novins, Jervis, Beals, \& the AI-SUPERPFP Team, 2013), further demonstrating the atypical nature of the particular subsample described in this paper. At the same time, we enter into this discussion precisely because these participants' perspectives on violence-as individuals who engage in the behavior and who meet the criteria for ASPD and comorbid alcohol use disorder-are especially valuable; indeed, this small subset of the 
population may disproportionately affect many individuals in their community. We argue further that the logic of violence that informs their actions is important to consider over and above its relationship to any particular diagnosis.

\section{Results}

We begin by describing the general characteristics of violence and providing a typology of violence by motivation, then move to an examination of the role of gender in violent encounters, followed by a discussion of how participants conceptualized their violent experience. Finally, we explore the implications of these findings for addressing violence in these communities. The word "motive" that appears in this violence typology was a category that evolved as part of the data analysis process. Other terms were considered, such as "explanation," "rationale," "justification," etcetera, but "motive" seemed uniquely able to capture participants' perspectives on what was driving violent episodes.

Overall, the reported violence among participants typically involved either fighting or being physically/sexually assaulted. Fighting occurred both in individual and group contexts, and there was a strong gender component to engagement with violence. Group fighting —or "ganging"- was most commonly engaged in by men. Although ganging could occur in the context of a formal gang, nearly all instances of group fighting described by participants here were not attributed to what they perceived to be formal gangs, but rather to gatherings of fluid and shifting groups of friends and/or relatives. However, similar characteristics are reportedly common among reservation gangs-described as typically unstructured, looseknit, and small (Ludden, 2009). Individual-level fighting was typically described merely as "fighting," and was engaged in by both men and women. Regardless of whether the violence occurred in group or individual settings, participants tended to focus on what motivated them to engage in this behavior. Accordingly, we present a typology of violence based on motives.

\section{Typologies of violence}

Local discourse on violence identified several different motives, which we have come to call reputation, leveling, retaliation, catharsis, and self-defense. These motives were not necessarily mutually exclusive; they commonly flowed into one another, as will become clear in our descriptions below, but distinguishing these motives seems to be especially indicated in an effort to understand where this violence may come from and what it means to the individuals who engage in it (see Table 2).

Reputation-Violence for reputation was a male phenomenon and was clearly intertwined with notions of masculinity. It occurred primarily in groups and was largely concerned with a desire to establish or preserve "one's name." Nineteen-year-old Ean believed that gang fighting was usually motivated by people "trying to upgrade their name or something ...just gain respect," to ensure that people knew one was a "tough guy." Fifty-year-old Pete, for example, proclaimed:

When we go out there, mention my name. Well, most of the time [people are] going to say, "Hey, stay away from that guy." Go to a club and mention my name 
over there, any place, [in the off-reservation border town], anywhere in the community.

For some, a desire to ward off future violence was embedded in reputational violence, which shades into the self-defense motive discussed below. Ean, for instance, remembered seeing someone show an AK47 to a group of young men looking for trouble: "That kind of respect kind of makes you the man, I guess, or something ...That kind of respect can make you not get beat up, basically." Those who engaged in violence for reputation tended to present it as inevitable within the sociocultural milieu of the reservation. Ean believed that someone who tried to avoid violence would be perceived as weak, and unless he had people stand up for him, he would be ganged. The way to gain respect was to fight. Similarly, 26-year-old Scott recalled,

As I was growing up, I tried to avoid fights like the way [my grandma] wanted me to, but then the kids-it's just like they harass you and harass you, so finally one day I threw what my grandma taught me aside for a little while and then I took care of things. Not the way anybody would, but the way I thought that it would make it right, so they'd quit harassing [me].

Violence for reputation was associated with starting fights or a reluctance to quit fighting when others were willing to call a truce. Twenty-nine-year-old Sam, for instance, described a gang fight between a few members of his family and another large family at a tribal fair. These families had been in a feud for the past 15 years:

There was four of us. There was a whole clan and some more people backing them up against four of us. And I looked at my brothers and I didn't know if they wanted to or not, but I sure as hell did. And I told them, I said, "My brothers," I said, "Cousin," I said, "It's only going to hurt for a little while." I said, "Let's go for it." There was close to two thousand people watching us. I said, "If we back down, they're never going to let us live it down." I said, "That doesn't even matter. Let's show these trash what we're made of." So they said, "Alright." Turns out they wanted to call a truce. And I said, "No, no, no, no, no." ...I said, "All of you are bitches."

As Sam watched his relatives shake hands with the rival family, he spit at them and walked away to preserve his reputation.

Leveling-Engaged in by both men and women and individually as well as in groups, violence for leveling sought to socially "bring down" another person. The underlying emotion in leveling appeared to be irritation or jealousy paired with a desire to restore a sense of equivalent social status. Sometimes the goal was to "knock down" a perceived braggart or a "BS-er" who was getting on one's nerves, as in the case of Sam, who let a used car dealer "have it" to stop his "BS-ing." Outright jealousy was often the primary impetus for violence for leveling. Ean described how a group of his female friends became objects of jealousy by another group of "lower class" girls. In this case, the women did not fight these battles directly; instead, groups of affiliated men fought as proxies. Although violence for leveling bore some resemblance to violence for reputation to the extent that bringing 
someone else down might elevate one's own reputation, preserving one's reputation was not at its forefront.

Retaliation-Described by both genders, revenge was the primary aim for some violence. Thirty-four-year-old Carol, while partying in a border town, had recently gotten into a gang fight with a group of women "for a friend." Specifically, Carol had beaten up a woman who had cheated with Carol's friend's husband. This group of women then tried to gang Carol in retaliation. It is clear here that loyalty also played a large role for Carol in her actions. As this example makes clear, retaliation could occur on a one-to-one basis or in a group context.

Catharsis-Some violence might best be described as cathartic. Only discussed by males in this select sample, this motive shaped fighting between individuals or in groups. The purgative quality of violence is made clear in Sam's statement:

All the shit that builds up on me, I guess, whatever gets in my way ...When I'm done [fighting], I usually just feel so tired, like I don't have any problems anymore. Just relaxed, and that's when I start buying the beer.

This violence was often perceived as enjoyable or a form of stress relief. For example, over the years, Pete had been in many fights, some so serious that he himself or someone else was nearly beaten to death. In fact, one of these assaults resulted in his being imprisoned for 15 years for nearly killing someone while drunk. Of fighting, Pete said, "I enjoyed it, you know. In my younger days I used to box quite a bit too." Similarly, Ean proclaimed, "It's pretty fun to let your emotions out." For those who engaged in violence for these reasons, then, it often appeared to provide something akin to the emotional and physical release of a good workout.

Self-defense-Of all the motives for violence reported here, self-defense was the most common, primarily because it motivated most of the violence described by the women in the sample (although as previously discussed, self-protection was not an insignificant component of men's reputational violence). While women were generally less involved in group fighting, nearly all of the women in this sample reported "fighting back" in situations of domestic violence. Such a tendency is true in the general population as well (Miller, 2001). For example, 41-year-old Sheila, who had a long history of child abuse and intimate partner violence, stated, "I feel anger a lot. Sometimes I feel anger because I was abused ... Sometimes I just get scared because I feel like I'm gonna lose it if somebody does something wrong to me." Somewhat differently, 33-year-old Kim was stabbed in the hand in an attempt to protect her infant son from her abusive husband.

One time he was drunk and we were drinking. I only had two kids for him then and [my son] was just a baby then, almost a baby, and he kept crying and we was standing at the kitchen and he was so drunk he don't remember grabbing a knife, 'cuz [my son] wouldn't stop crying. And he said, "Make him be quiet!" and he went down like that with a knife, so if I didn't put my hand up, he woulda hit my baby in the face.

Unlike violence for reputation, leveling, retaliation, and catharsis, which were most often group events, fighting with the explicit motive of self-defense was always a one-to-one 
activity. Hence, a woman's attempt to defend herself against her male abuser was typically a solo endeavor among participants, whereas men could often count on the backing of their buddies in their communal fighting experiences, even if this also served defensive purposes.

\section{Gender and fighting}

As this discussion suggests, violence was gendered in important ways in this sample.

Violence for reputation and catharsis were the exclusive province of men, whereas both men and (a smaller number of) women discussed engaging in violence for leveling and retaliation, and self-defense was most often reported as an explicit motive by women.

Men much more frequently described behavior consistent with being in a perpetrator role than did women. Indeed, an examination of ethnographic and clinical interview transcripts found that only a third of women described inflicting violence in a situation other than selfdefense, whereas nearly all men reported having done so. Men in general reported much less victimization as children and no victimization by domestic violence. In contrast, all of the women in this sample reported having been subject to considerable-and sometimes horrific - domestic violence, including being beaten, choked, stabbed, and run over by a car. Most women had experienced severe child physical and sexual abuse in addition to sexual assaults as adults. Compared to women's complicated accounts, then, men's accounts seemed rather straightforward. In their discourse, men rarely presented themselves as victims and often represented themselves exclusively as perpetrators, while women frequently represented themselves as victims who acted violently in order to defend themselves.

\section{Participants' conceptualizations of violence}

The anger described by participants was seldom directed at people, forces, or institutions outside of the reservation. Neither was this anger explicitly directed at oneself. The vast majority of anger was instead directed at fellow tribal members, be they rivals, family members/relatives, or nonrelated community members. Interestingly, many participants denied starting any fights themselves. Instead, violence for these individuals was, in their view, either understandable or the best option given the circumstances in which they lived. Ean, for instance, proclaimed that he generally kept things bottled up, and for this reason, in a fight he had "a tendency to not stop when they're down," meaning someone always had to stop him "before it gets too far." Despite this, Ean stated, "I don't consider myself a violent person, though. It's just the environment I'm in ...If I' $m$ in a good environment, I'm a pretty good person, but when I'm in a chaotic environment, then I kind of get crazy." Sam went further and blamed his behavior on reservation life itself:

I never felt like fighting was right, but it always seemed like I've had to do it. It's always something that I've felt that I've had to do, whether I'm outnumbered-a lot of times I felt that this guy is just not going to quit—he's just not going to quit unless I whip his ass. And that's the way it is on this rez ...If you turn your back on somebody, it's your own fault for whatever happens after that. This rez ain't a cool place to live. Somebody got a problem with you and you try to walk away from it, they're not going to let you. They're going say that you're chicken shit. That's going to fire them up even more. 
In Sam's view, life on the reservation meant fighting. Moreover, it was the individual's responsibility to take care of oneself, including the need to bear the consequences of not reacting in a violent manner. This is suggestive of the kind of adaptive survival strategy that the DSM-IV cautions practitioners to take into consideration when diagnosing ASPD among impoverished individuals (American Psychiatric Association, 1994).

Although participants generally did not attribute their violent actions directly to alcohol, it was nonetheless inextricably interwoven with violent experiences, as it is among the general population (Lipsey, Wilson, Cohen, \& Derzon, 1997; Scott, Schafer, \& Greenfield, 1999). Most of the violent encounters described here by men occurred during episodes of alcohol intoxication; drugs were very rarely mentioned. Similarly, alcohol was often involved in women's violent encounters, although in more complex ways. Sometimes male perpetrators were described by female participants as being under the influence, while they themselves were not; at other points, domestic violence occurred while both partners were drunk. In yet other incidences, domestic or sexual violence led women to engage in what seemed to be a kind of defensive drinking in reaction to their abuser's drinking and/or abuse. And although a few of the men in this sample reported fighting — or fighting better or more brutallywhen sober, alcohol has been found to increase the likelihood of physical assault and injury during interpersonal conflicts in the general population (Martin \& Bachman, 1997).

Given participants' representation of violence as inevitable, it is not terribly surprising that very few participants expressed remorse at the violent acts they committed. In Pete's view, those he fought against deserved it.

Like I say, a lot of them, you know, they challenged me ...I'm gonna try to beat the shit out of them good. I want to make sure they remember it, you know, they won't bother me anymore or anybody else, for that matter.

And many, like Sam, described violence in dispassionate terms. Reflecting on having witnessed a man get stabbed, Sam stated:

I think that it's supposed to be wrong, yet people just ...that's life as usual for them so it ...I don't even give a shit myself ...I was like, "Huh, I learn something new every day. See how far a guy's eyes pop out."

Especially when violence was leveled at those who were themselves violent, little sympathy was expressed.

Sam's case, though, illustrates that violent tendencies do not come out of nowhere. Raised by an alcoholic mother who was herself violent, Sam described severe beatings at her hands as a child. He recalled being locked in his room with bars placed over the windows so that he couldn't escape. He also experienced numerous tragedies, including the deaths of his father in a car accident and brother to suicide at a young age. And, even though his adult life was largely comprised of heavy drinking, auto races and accidents, and brutal gang fights, Sam reported having quite a soft spot for his own children and those in his neighborhood.

As Sam's case illustrates, a sense of morality was to be found even among those most likely to be seen as amoral by those outside the subcultures to which these individuals belonged. 
This was expressed in notions of deservingness, especially with respect to the appropriate targets of violence (e.g., the violent deserve violence, innocent children do not). Variation in remorse and in insight is displayed in the example of 26-year-old Scott, who stated that he almost killed people on two occasions for reasons he did not understand. Scott, unlike some of the other participants, regretted having caused harm to his victims, although he realized that those regrets would not change anything. Noting that he had been deemed "homicidal" by several mental health professionals, Scott stated that he was not "normal," that he had a "flaw," and that he wanted to know what was wrong with him. And although not explicitly about their own violence perpetration, remorse was expressed quite clearly among women who had children taken away because of domestic violence, alcohol abuse, and child neglect. Losing one's children appeared to be more significant than having been the victim of domestic violence oneself.

Further, some participants acknowledged that their violence was incompatible with tribal religion. Thirty-four-year-old Van was seriously assaulted and robbed by a group of men while drunk. He had much physical difficulty after "being ganged" and perseverated about killing the men, but said he did not want to kill them: "Sometime I go to sweats, pray for those people ...I can be bad if I want, but I don't want to."

Likewise, Carol found traditional religion to be helpful in understanding the implications of her anger:

I go and pray whenever I start trying to lose my temper, "cause about three weeks ago I was kind of feeling empty inside and I couldn't understand it and my aunt happened to invite me to a ceremony, so I went, prayed, and then that soon ... inside that ceremony I was able to realize that it was my anger that was consuming me and making me empty.

Ironically, though, Carol's tendencies toward violence also limited her involvement in religion.

It's my wild side that I can't even touch that pipe. I just can't. I've got too much aggression or whatever. 'Cause they say that you ain't supposed to, you know, hit a person or fight or lose your temper or anything like that. But I do. And I can't touch that pipe, but I go and pray. They pray for me.

Although Carol was capable of making herself "think positive" and "behave" for a week or so during the Sundance or while praying with a relative, she would soon return to "going back to me-being me." She believed that she remained, at her core, a "bad seed," so bad she could only maintain a distant relationship with her religion. Yet, this respect for traditional religion and her acknowledgement that she did not meet the requirements for deeper involvement suggests that she was at least at some level attuned to and adhering to cultural notions of morality.

Thus, although many participants professed to being untroubled by their violence, or even proud of it, there were hints of recognition among some that this was not how life was supposed to be. We close with a discussion of some of the ongoing questions our study has 
raised, as well as the implications of this testimony for community responses to violence more generally.

\section{Discussion}

This study, which originally sought to understand the phenomenology and patterning of violence on a northern plains reservation, has led us to question some of its driving forces in this sample with ASPD and alcohol use disorder. As we examined participants' accounts in detail, we began to understand the logic that shaped each individual's recourse to violence. Yet, in many ways, these explanations have raised as many questions as they have answered. For one, the relationship among violence, ASPD, and alcohol is exceedingly complex. The linkages between problematic alcohol use and violence in this sample pose intriguing but ultimately unanswerable questions about what participants' violence profiles would have looked like had they not been abusing alcohol. Although impossible to say with certainty, without alcohol, it seems likely that some of this violence would have been muted. Our goal in this study was to understand the logic by which violence may make sense for these individuals. We do not claim that their answers are definitive, nor that they are merely irrelevant rationalizations for drunken behavior beyond all conscious control. Ever since MacAndrew and Edgerton's (1969) Drunken Comportment, anthropologists have examined the cultural construction of drunken behavior (including elements of choice), and this work provides ample evidence for the interactions of drunkenness with local cultural worlds. That is the line we pursue here, where a logic of fear and protection, or insult and honor, colors the perspectives of this subset of the population. Further, our argument is that understanding the viewpoint of these individuals may be an important component of addressing their violence, whatever the ultimate validity of claims about violent incidents.

In many respects, the participants in this study resembled people with ASPD generally, exhibiting symptoms such as aggressiveness, recklessness, and lack of remorse. These symptoms were not novel, but by examining the violence of individuals who met the criteria for ASPD in its social and cultural context, a number of perspectives emerge. Most interesting are the varied motives for engaging in violence and the ways in which these were shaped by gender. While men described themselves as ready participants in a violent world, even acknowledging pleasure in violence (as in their discussions of catharsis), women were quite clear that violence was often simply required as they tried to defend themselves from the violence of men.

If, indeed, violence was simply seen as the best choice in some very constrained circumstances for some of this study's participants, then the obvious question is how the dynamics of violence here compare to those in other communities, especially impoverished communities comprised of individuals who have been discriminated against on the basis of race/ethnicity. Here Ness's (2004) study of the street fighting of inner-city adolescent girls in Philadelphia may be especially relevant. For instance, the "identity enhancement" emphasis described by Ness resembled the importance of reputation described among our participants, which also echoes the importance of respect that Bourgois (2002) found among Puerto Rican crack dealers. Likewise, catharsis, with its combination of release and pleasure, was similar to the purgative, pleasurable, and sports-like elements of street- 
fighting among Ness's informants. The motivations described in those studies more closely resembled those found among this study's male participants. Nonetheless, these commonalities suggest that these aspects of violence may be more widespread and related to structural features of poverty and oppression, especially in impoverished and marginalized communities searching for respect, than to "essentialized" culturally specific traits per se. This is not to say that all inhabitants are equally concerned with obtaining respect, or that only one path exists for achieving it within such communities, but that poor communities do face a number of constraints that limit opportunities found elsewhere within the larger society. In such settings, those with a predisposition toward violence might find themselves funneled toward limited, destructive channels that are more readily available to them.

Hence, a question that emerges from these findings relates to sociocultural milieu, violence, and the diagnosis of ASPD. The most pertinent consideration here is the extent to which at least some of the violence that participants describe makes sense as an understandable response to the dangerous environments in which these individuals live, be it the all-too-real possibility of victimization for women or the need to assert a masculine self in a context where winning fights seems required both to establish one's reputation and to prevent future assaults. Here it is also important to consider the inadequate law enforcement and systemic jurisdictional problems found on many reservations. Owing to funding inadequacies and the complex jurisdictional situation imposed by American Indian Nations' incomplete sovereignty, the end result is often a lack of prosecution of violent crimes on reservations that then contributes to lack of safety within Native communities (Amnesty International, 2007; Biolsi, 2005; Wakeling, Jorgensen, Michaelson, \& Begay, 2001). Of course, it is equally important to acknowledge that many individuals in similar circumstances do not develop ASPD or resort to the violent behavior described here. A number of factors might account for this, with resilience (both on an individual and community level) likely playing some role (Jervis \& the AI-SUPERPFP Team, 2009), and exploring the logic by which violence is averted by individuals in similar circumstances may be another fruitful line of inquiry.

In this vein, it is important to emphasize that this is a clinical sample, and the motivations for violence identified here might appear to be little more than justifications and rationalizations for destructive behavior in a small minority of individuals who make these choices. Indeed, one of the hallmarks of ASPD, according to the DSM-IV, is the tendency to be

indifferent to, or provide a superficial rationalization for, having hurt, mistreated, or stolen from someone (e.g., "life's unfair," "losers deserve to lose," or "he had it coming anyway"). These individuals may blame the victim for being foolish, helpless, or deserving their fate; they may minimize the harmful consequences of their actions; or they may simply indicate complete indifference. (American Psychiatric Association, 1994, p. 646)

Many of the participants in this study did express these kinds of views, and hence may have been trying to justify their behavior. The question here is what it means to justify exceptional violence in a cultural milieu where at least some of these safety concerns are in fact real. 
In conclusion, the participants presented here are a "tough group," both with regard to their personal presentations and their therapeutic and rehabilitational prospects in light of their well-established violent and diagnostic histories. Expressions of straightforward remorse or desire for change were sparse. Likewise, the connection between domestic violence and ASPD was disturbing, since women's violence occurred largely in the context of selfdefense. At the same time, the complexities around this violence suggest some of the possibilities that may exist for transforming the pursuit of reputation, leveling, retaliation, catharsis, and self-defense into nonviolent behavior. One such possibility is the complex interplay between problematic drinking and antisociality, given the ways in which these behaviors were interwoven. Yet another possible point of intervention is creating opportunities within communities for young men to further engage their desire for reputational enhancement and cathartic outlet in a manner that both they and the larger community deem as productive rather than destructive. One area for future research is the role of early developmental trauma in relation to later pathological responses, such as ASPD, in this population. Experiencing adverse childhood events (abuse, neglect, and maltreatment) has been consistently related to later criminal behavior and violence against others. Chronic maltreatment is thought to have pervasive developmental effects that can translate to later behavioral consequences such as violent behaviors (van der Kolk, 1989, 2005). Regardless, these findings point to the importance of taking into account cultural context and insiders' views of what drives violent behavior, especially when it comes to treatment expectations and planning.

\section{Acknowledgements}

We wish to thank the tribal members who so generously volunteered their time to take part in this study.

Funding

This research was funded by the following grants from the National Institute on Mental Health: R01 MH073965 (Janette Beals, PI); R01 MH48174 (Spero M. Manson, PI); and P01 MH42473 (Spero M. Manson, PI).

\section{References}

Alarcon RD, Foulks EF. Personality disorders and culture: Contemporary clinical views (Part A). Cultural Diversity and Mental Health. 1995; 1(1):3-17. [PubMed: 9225544]

American Psychiatric Association. Diagnostic and statistical manual of mental disorders, fourth edition: DSM-IV. 4th ed.. Washington, DC: Author; 1994.

Amnesty International. Maze of injustice: The failure to protect Indigenous women from sexual violence in the USA. Leicester, UK: Author; 2007.

Beals J, Manson SM, Mitchell CM, Spicer P. the AI-SUPERPFP Team. Cultural specificity and comparison in psychiatric epidemiology: Walking the tightrope in American Indian research. Culture, Medicine and Psychiatry. 2003; 27:259-289.

Beals J, Manson SM, Whitesell NR, Spicer P, Novins DK, Mitchell CM. Prevalence of DSM-IV disorders and attendant help-seeking in two American Indian reservation populations. Archives of General Psychiatry. 2005; 62:99-108. [PubMed: 15630077]

Biolsi T. Imagined geographies: Sovereignty, Indigenous space, and American Indian struggle. American Ethnologist. 2005; 32(2):239-259.

Bourgois, P. In search of respect: Selling crack in El Barrio. 2nd ed.. New York, NY: Cambridge University Press; 2002. 
Braveheart-Jordan, M.; DeBruyn, L. So she may walk in balance: Integrating the impact of historical trauma in the treatment of Native American Indian women. In: Adleman, J.; Enguidanos, GM., editors. Racism in the lives of women: Testimony, theory, and guides to antiracist practice. New York, NY: Haworth Press; 1995. p. 345-368.

Buchwald D, Tomita S, Ashton S, Furman R, Manson SM. Physical abuse of urban Native Americans. Journal of General Internal Medicine. 2000; 15:562-564. [PubMed: 10940148]

Cale EM, Lilienfeld SO. Sex differences in psychopathy and antisocial personality disorder: A review and integration. Clinical Psychology Review. 2002; 22(8):1179-1207. [PubMed: 12436810]

Carson, DK.; Hand, C. Dilemmas surrounding elder abuse and neglect in Native American communities. In: Tartara, T., editor. Understanding elder abuse in minority populations. Philadelphia, PA: Brunner/Mazel; 1999. p. 161-184.

Chester B, Robin RW, Koss MP, Lopez J, Goldman D. Grandmother dishonored: Violence against women by male partners in American Indian communities. Violence and Victims. 1994; 9(3):249258. [PubMed: 7647046]

Collins JJ, Schlenger WE. Acute and chronic effects of alcohol use on violence. Journal of Studies on Alcohol. 1988; 49(6):516-521. [PubMed: 3236883]

Compton WM, Thomas YF, Stinson FS, Grant BF. Prevalence, correlates, disability, and comorbidity of DSM-IV drug abuse and dependence in the United States: Results from the National Epidemiologic Survey on Alcohol and Related Conditions. Archives of General Psychiatry. 2007; 64(5):566-576. [PubMed: 17485608]

DeBruyn L, Chino M, Serna P, Fullerton-Gleason L. Childmal-treatment in American Indian and Alaska Native communities: Integrating culture, history, and public health for intervention and prevention. Child Maltreatment. 2001; 6(2):89-102. [PubMed: 16705785]

Duran, E.; Duran, B.; Yellow Horse Brave Heart, M.; Yellow Horse-Davis, S. Healing the American Indian soul wound. In: Danieli, Y., editor. International handbook of multigenerational legacies of trauma. New York, NY: Plenum Press; 1998. p. 341-354.

Eckholm E. Gang violence grows on an Indian reservation. The New York Times. 2007 Dec 13. Retrieved from http://www.nytimes.com/2009/12/14/us/14gangs.html?pagewanted=all\&_r=0.

Evans CM. Alcohol, violence and aggression. Alcohol and Alcoholism. 1980; 15(3):104-117.

Evans-Campbell T, Lindhorst T, Huang B, Walters KL. Interpersonal violence in the lives of urban American Indian and Alaska Native women: Implications for health, mental health, and helpseeking. American Journal of Public Health. 2006; 96:1416-1422. [PubMed: 16809604]

Everett, MW. Drinking as a measure of proper behavior: The White Mountain Apaches. In: Waddell, JO.; Everett, MW., editors. Drinking behavior among Southwestern Indians: An anthropological perspective. Tucson, AZ: University of Tucson Press; 1980. p. 148-177.

Fickenscher A, Novins DK, Jervis LL, Beals J. the AI-SUPERPFP Team. Antisocial personality disorder among two American Indian reservation populations. 2013 Manuscript in preparation.

Fischler RS. Child abuse and neglect in American Indian communities. Child Abuse and Neglect. 1985; 9(1):95-106. [PubMed: 4038906]

Grant BF, Hasin DS, Stinson FS, Dawson DA, Chou SP, Ruan WJ, Pickering RP. Prevalence, correlates, and disability of personality disorders in the United States: Results from the National Epidemiological Survey on Alcohol and Related Conditions. Journal of Clinical Psychiatry. 2004; 65:948-958. [PubMed: 15291684]

Grant BF, Stinson FS, Dawson DA, Chou SP, Ruan WJ, Pickering RP. Co-occurrence of 12-month alcohol and drug use disorders and personality disorders in the United States: Results from the National Epidemiologic Survey on Alcohol and Related Conditions. Archives of General Psychiatry. 2004; 61(4):361-368. [PubMed: 15066894]

Grant CM, Feimer S. Street gangs in Indian country: A clash of cultures. Journal of Gang Research. 2007; 14(4):27-66.

Gray K. Brave new world: Poverty, alcoholism, and drugs have born a generation of gangs that are turning a South Dakota reservation into South Central. Details. 2009 Retrieved from http:// www.details.com/culture-trends/news-and-politics/200608/south-dakota-reservation-has-becomegang-territory. 
Greenfeld, LA.; Smith, SK. American Indians and crime. Washington, DC: U.S. Department of Justice; 1999.

Guest, G.; MacQueen, KM. Handbook for team-based qualitative research. Lanham, MD: Altamira Press; 2008.

Hudson MF, Armachain WD, Beasley CM, Carlson JR. Elder abuse: Two Native American views. The Gerontologist. 1998; 38(5):538-548. [PubMed: 9803642]

Jervis LL, Spicer P, Manson SM. the AI-SUPERPFP Team. Boredom, "trouble," and postcolonial reservation life. Ethos. 2003; 31(1):38-58.

Jervis LL. the AI-SUPERPFP Team. Disillusionment, faith, and cultural traumatization on a Northern Plains reservation. Traumatology. 2009; 15(1):11-22.

Kessler RC, McGonagle KA, Zhao S, Nelson CB, Hughes M, Eshleman S, Wittchen HU, Kendler KS. Lifetime and 12-month prevalence of DSM-III-R psychiatric disorders in the United States. Archives of General Psychiatry. 1994; 51:8-19. [PubMed: 8279933]

Kunitz, SJ.; Levy, JE. Drinking, conduct disorder, and social change: Navajo experiences. New York, NY: Oxford University Press; 2000.

Levy, JE.; Kunitz, SJ. Indian drinking: Navajo practices and Anglo-American theories. New York, NY: John Wiley and Sons; 1974.

Lipsey MW, Wilson DB, Cohen MA, Derzon JH. Is there a causal relationship between alcohol use and violence? A synthesis of evidence. Recent Developments in Alcoholism. 1997; 13:245-282. [PubMed: 9122498]

Ludden J. Gang violence on the rise on Indian reservations. 2009 Aug 25. Retrieved from http:// www.npr.org/templates/story/story.php?storyId=112200614.

Lynn R. Racial and ethnic differences in psychopathic personality. Personality and Individual Differences. 2002; 32(2):273-316.

MacAndrew, C.; Edgerton, RB. Drunken comportment: A social explanation. Chicago, IL: Aldine; 1969.

Malley-Morrison, K.; Hines, DA. Family violence in a cultural perspective: Defining, understanding, and combating abuse. Thousand Oaks, CA: Sage; 2004.

Manson SM, Beals J, Klein S, Croy CD. the AI-SUPERPFP Team. The social epidemiology of trauma in two American Indian reservation populations. American Journal of Public Health. 2005; 95(5): 851-859. [PubMed: 15855465]

Martin SE, Bachman R. The relationship of alcohol to injury in assault cases. Recent Developments in Alcoholism. 1997; 13:41-56. [PubMed: 9122504]

Miller SL. The paradox of women arrested for domestic violence: Criminal justice professionals and service providers respond. Violence Against Women. 2001; 7(12):1339-1376.

Moeller FG, Dougherty DM. Antisocial personality disorder, alcohol, and aggression. Alcohol, Research, \& Health. 2001; 25(1):5-11. [PubMed: 11496966]

Murdoch D, Pihl RO, Ross D. Alcohol and crimes of violence: Present issues. The International Journal of the Addictions. 1990; 25(9):1065-1081. [PubMed: 2090635]

Ness CD. Why girls fight: Female youth violence in the inner-city. Annals of the American Academy of Political and Social Science. 2004; 595:32-48.

Norton IM, Manson S. Domestic violence intervention in an urban Indian health center. Community Mental Health Journal. 1997; 33:331-337. [PubMed: 9250430]

Nuckolls CW. Toward a cultural history of the personality disorders. Social Science \& Medicine. 1992; 35(1):37-47. [PubMed: 1496411]

Oetzel J, Duran B. Intimate partner violence in American Indian and/ or Alaska Native communities: A social ecological framework of determinants and interventions. American Indian and Alaska Native Mental Health Research. 2004; 11(3):49-69. [PubMed: 15536589]

O'Reilly, K. Key concepts in ethnography. Los Angeles, CA: Sage; 2009.

Pernanen, K. Alcohol in human violence. New York, NY: Guilford Press; 1991.

Perry, SW. American Indians and crime: A BJS statistical profile, 1992-2002. Washington, DC: U.S. Department of Justice; 2004. 
Qualitative Solutions \& Research. NUDIST Vivo 7 (NVivo 7, Version 7) [Computer software]. Melbourne, Australia: QSR International Pty Ltd; 2006.

Rutherford M, Alterman A, Cacciola J, Snider E. Gender differences in diagnosing antisocial personality disorder in methadone patients. American Journal of Psychiatry. 1995; 152(9):1309_ 1316. [PubMed: 7653686]

Sandelowski A. The problem of rigor in qualitative research. Advances in Nursing Science. 1986; 8(3):27-37. [PubMed: 3083765]

Scott KD, Schafer J, Greenfield TK. The role of alcohol in physical assault perpetration and victimization. Journal of Studies on Alcohol. 1999; 60(4):528-536. [PubMed: 10463810]

Skeem JL, Edens JF, Sanford GM, Colwell LH. Psychopathic personality and racial/ethnic differences reconsidered: A reply to Lynn (2002). Personality and Individual Differences. 2003; 35(6):1439_ 1462.

Spicer P. Toward a (dys)functional anthropology of drinking: Ambivalence and the American Indian experience with alcohol. Medical Anthropology Quarterly. 1997; 11(3):306-323. [PubMed: 9292860]

Spitzer, RL.; Williams, J.; Gibbon, M. Structured clinical interview for DSM-III-R, Version NP-V. New York, NY: New York Psychiatric Institute, Biometrics Research Department; 1987.

Strauss, A.; Corbin, J. Basics of qualitative research: Grounded theory procedures and techniques. Newbury Park, CA: Sage; 1990.

U.S. Census Bureau. The American community_American Indians and Alaska Natives: 2004. 2007. Retrieved from http://www.census.gov/prod/2007pubs/acs-07.pdf

Van der Kolk BA. The compulsion to repeat the trauma: Re-enactment, revictimization, and masochism. Psychiatric Clinics of North America. 1989; 12(2):389-411. [PubMed: 2664732]

Van der Kolk BA. Developmental trauma disorder. Psychiatric Annals. 2005; 35(5):401-408.

Wahab S, Olson L. Intimate partner violence and sexual assault in Native American communities. Trauma Violence Abuse. 2004; 5(4):353-366. [PubMed: 15361588]

Wakeling, S.; Jorgensen, M.; Michaelson, S.; Begay, M. Policing on American Indian reservations: A report to the National Institute of Justice. Washington, DC: 2001.

Whitbeck LB, Adams GW, Hoyt DR, Chen X. Conceptualizing and measuring historical trauma among American Indian people. American Journal of Community Psychology. 2004; 33(3-4): 119-130. [PubMed: 15212173]

Zuckerman M. Are there racial and ethnic differences in psychopathic personality? A critique of Lynn's (2002) racial and ethnic differences in psychopathic personality. Personality and Individual Differences. 2003; 35(6):1463-1469.

\section{Biographies}

Lori L. Jervis, PhD, is Associate Professor of Anthropology and an Allied Center Director of the Center for Applied Social Science at the University of Oklahoma. A cultural/medical anthropologist, Dr. Jervis has conducted federally funded research on American Indian mental and cognitive health, trauma, and violence. She served as an ethnographer in her former faculty position at the Centers for American Indian and Alaska Native Health at the University of Colorado Anschutz Medical Campus. Dr. Jervis was Principal Investigator of a collaborative research project on elder abuse among American Indians in rural reservation and urban contexts funded by the National Institute of Aging. She has published numerous articles in psychiatric anthropology, neuropsychiatry, and gerontology.

Paul Spicer, $\mathrm{PhD}$, is Professor of Anthropology and an Allied Center Director at the Center for Applied Social Research at the University of Oklahoma. His research and scholarship focuses on substance abuse, mental health, and child development in American Indian and Alaska Native communities. He has led over a dozen research projects in these areas, with 
funding from the Administration on Children and Families, numerous institutes at NIH, and the Robert Wood Johnson Foundation.

Annie Belcourt (Otter Woman), $\mathrm{PhD}$, is an American Indian assistant professor in the College of Health Professions and Biomedical Sciences at the University of Montana's Pharmacy Practice and School of Public and Community Health Sciences departments (enrolled tribal member of the Three Affiliated Tribes: affiliation: Mandan, Hidatsa, Blackfeet, and Chippewa). She directs the college's Health Disparities Initiatives, teaches, and conducts mixed methods research. Her doctorate is in clinical psychology and her research and clinical practice priorities include mental health disparities, exposure to trauma, posttraumatic stress reactions, risk, resiliency, psychiatric disorder, and sexual risk within the cultural context of American Indian communities.

Michelle Sarche, $\mathrm{PhD}$, is a clinical psychologist and Associate Professor in the Centers for American Indian and Alaska Native Health, at the University of Colorado Anschutz Medical Campus, Colorado School of Public Health, Department of Community and Behavioral Health. Dr. Sarche's clinical activities and research have focused on understanding the challenges to, and supports for, health across the lifespan. Her published works focus on children's development, parenting, mental health, and engaged scholarship in tribal communities. Dr. Sarche's serves as the Director of Research Training and Information Dissemination for the Tribal Early Childhood Research Center, codirects the Native Children's Research Exchange, and leads a project to understand the relationship between stress and early development among American Indian children and their parents. She is a member of the Lac Courte Oreilles Band of Ojibwe.

Douglas K. Novins, MD, is the Cannon Y. \& Lyndia Harvey Chair in Child and Adolescent Psychiatry; Chair, Department of Psychiatry \& Behavioral Sciences, Children's Hospital Colorado; Professor, Vice Chair, \& Director, Division of Child \& Adolescent Psychiatry, Department of Psychiatry, University of Colorado School of Medicine; and Professor of Community \& Behavioral Health, Centers for American Indian \& Alaska Native Health, Colorado School of Public Health. Dr. Novins researches mental health and substance abuse services for American Indian and Alaska Native Mental Health populations. He is currently the Principal Investigator of the Tribal Early Childhood Research Center (ACF) and Evidence-Based Practices and Substance Abuse Treatment for Native Americans Project (NIDA). Dr. Novins is also co-investigator of the Center for American Indian and Alaska Native Health Disparities (NIMHD). His published works focus on psychiatric epidemiology, developmental psychopathology, and mental health services research.

Alexandra Fickenscher, MPH, is a former senior professional research assistant at the Centers for American Indian and Alaska Native Health at the University of Colorado Anschutz Medical Campus, Aurora, CO. Her published works focus on issues of mental health and substance abuse among American Indian youth and adults.

Janette Beals, $\mathrm{PhD}$, is the Director of Research at the Centers for American Indian and Alaska Native Health (CAIANH) and a professor at the Colorado School of Public Health at the University of Colorado Anschutz Medical Campus. With over 100 publications, she has 
written extensively about topics including: methodological issues, measure development, epidemiological descriptions of American Indian mental health/substance use, and descriptions of service use patterns in American Indian communities. 


\section{Total (NP and SW) Al-SUPERPFP random sample $=3,084$}

NP SCID sample $=217$

$$
\text { NP CIDI sample }=1,638
$$

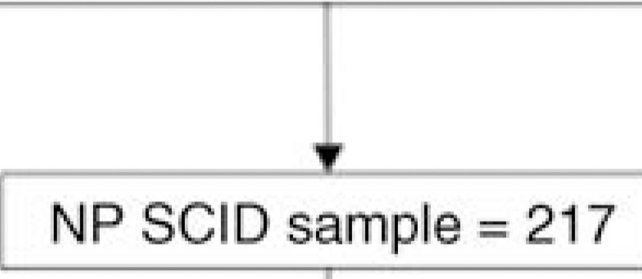

NP ethnographic interview sample $=44$

NP clinigraphy participants with ASPD $=15$

Figure 1.

Northern plains AI-SUPERPFP sampling strategy. 
Table 1

Demographic characteristics of Grass River participants $(n=15)$.

\begin{tabular}{|c|c|c|}
\hline & $n$ & $\%$ \\
\hline \multicolumn{3}{|l|}{ Gender } \\
\hline Male & 7 & 46.7 \\
\hline Female & 8 & 53.3 \\
\hline \multicolumn{3}{|l|}{ Age } \\
\hline $15-24$ & 2 & 13.3 \\
\hline $25-34$ & 6 & 40.0 \\
\hline $35-44$ & 4 & 26.7 \\
\hline $45+$ & 3 & 20.0 \\
\hline \multicolumn{3}{|l|}{ Marital status } \\
\hline Married, living as married & 10 & 66.7 \\
\hline Separated, widowed, divorced & 1 & 6.7 \\
\hline Never married & 4 & 26.7 \\
\hline \multicolumn{3}{|l|}{ Education } \\
\hline$<12$ years & 7 & 46.7 \\
\hline Completed high school & 2 & 13.3 \\
\hline Some college & 6 & 40.0 \\
\hline \multicolumn{3}{|l|}{ Poverty status ${ }^{*}$} \\
\hline Nonpoor & 2 & 13.3 \\
\hline Poor & 11 & 73.3 \\
\hline \multicolumn{3}{|l|}{ Diagnosis } \\
\hline Antisocial personality disorder & 15 & 100.0 \\
\hline Alcohol abuse/dependence & 15 & 100.0 \\
\hline Major depressive disorder & 13 & 86.7 \\
\hline Posttraumatic stress disorder & 10 & 66.7 \\
\hline Drug abuse/dependence & 10 & 66.7 \\
\hline Panic disorder & 2 & 13.3 \\
\hline
\end{tabular}

* Missing data for two participants. 

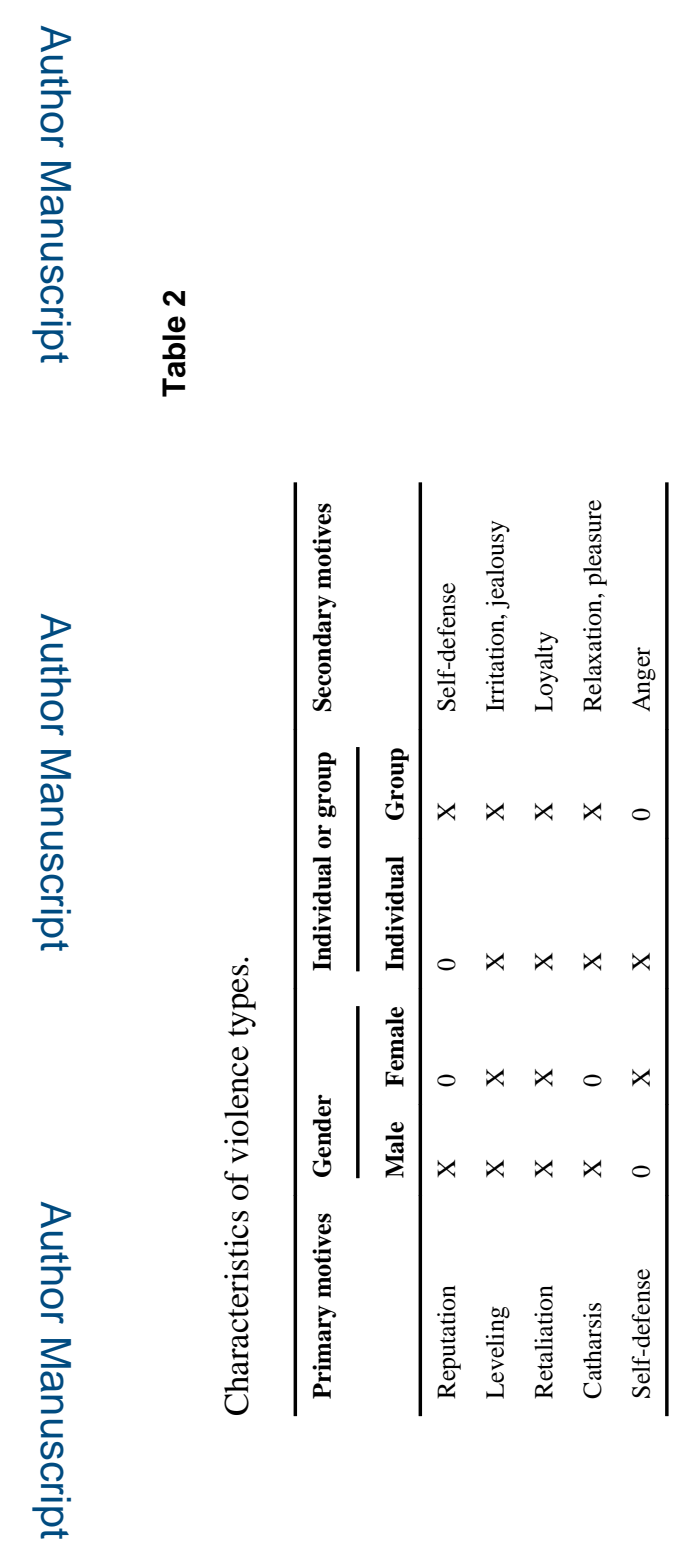

Transcult Psychiatry. Author manuscript; available in PMC 2015 August 10. 